\title{
A goal-systems perspective on plant-based eating: keys to successful adherence in university students
}

\author{
Maricarmen Vizcaino ${ }^{1}$ (D), Linda S Ruehlman ${ }^{2}$, Paul Karoly ${ }^{2,3}$, Katy Shilling ${ }^{1}$, \\ Andrew Berardy 4 , Sidney Lines ${ }^{5}$ and Christopher M Wharton ${ }^{1,4, *}$ \\ 'Nutrition Program, Radical Simplicity Lab, College of Health Solutions, Arizona State University, Phoenix, AZ 85004, \\ USA: ${ }^{2}$ Goalistics, LLC, Tempe, AZ 85287, USA: ${ }^{3}$ Department of Psychology, Arizona State University, Tempe, \\ AZ 85287, USA: ${ }^{4}$ Swette Center for Sustainable Food Systems, Arizona State University, Tempe, AZ 85281, USA: \\ ${ }^{5}$ Department of English, University of British Columbia, Vancouver, BC Canada
}

Submitted 8 October 2019: Final revision received 23 December 2019: Accepted 28 February 2020: First published online 9 June 2020

\begin{abstract}
Objective: To explore adherence to a plant-based diet from the perspective of goals- and motivations-based systems.

Design: A cross-sectional, survey-based study was conducted regarding eating patterns, goals and motivations for current eating habits.

Setting: Data were collected using an online survey platform, including the Goal Systems Assessment Battery (GSAB) and other survey tools.

Participants: University students were recruited, including thirty-three students reporting successful maintenance of a plant-based diet (Adherents) and sixty-three students trying to adhere to a plant-based diet (Non-adherents).

Results: Using GSAB subscale scores, discriminant function analyses significantly differentiated adherents $v$. non-adherents, accounting for $49.0 \%$ of between-group variance $\left(\chi^{2}(13)=42.03, P<0.000\right)$. It correctly classified $72.7 \%$ of adherents and $88.9 \%$ of non-adherents. Constructs including value, self-efficacy, planning/ stimulus control and positive affect were significant and included in the discriminant function. Logistic regression results suggested that participants who successfully adhered to a plant-based diet were seventeen times more likely to report 'To manage or treat a medical condition' as motivation and almost seven times more likely to report 'To align with my ethical beliefs' as motivation compared with non-adherents. However, these participants were $94 \%$ less likely to report 'To maintain and/or improve my health' as motivation compared with non-adherents. Controlling for motivations, hierarchical logistic regression showed that only planning as part of the GSAB self-regulatory system predicted adherence to a plant-based diet.

Conclusions: Values-based approaches to plant-based diets, including consideration for ethical beliefs, self-efficacy and proper planning, may be key for successful maintenance of this diet long-term.
\end{abstract}

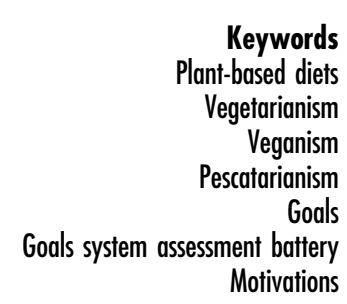

Interest in plant-based diets continues to grow with increasing market availability of alternative protein products as well as consumer demands for foods that are perceived to be healthful, ethical and sustainable ${ }^{(1,2)}$. Common plant-based dietary patterns include veganism (total elimination of animal-based foods), lacto-ovo-vegetarianism (which excludes animal-based foods other than eggs and dairy), flexitarianism (which is generally vegetarian but rarely to occasionally includes meat or fish) and pescatarianism (which excludes animal-based foods other than eggs, dairy and fish $)^{(3,4)}$. The health benefits provided by plant-based diets are abundant, notably including more consistent weight management, reduced blood pressure and improved lipid profile ${ }^{(5-8)}$. These and other improved markers of health likely contribute to the role plant-based diets may play in decreasing risk for all-cause mortality, lower prevalence of metabolic syndrome and diabetes, lower incidence of heart disease and total cancers and decreased odds for developing overweight and obesity over time ${ }^{(9-11)}$. And while plant-based diets can be effective

*Corresponding author: Email cwharton@asu.edu

(C) The Author(s) 2020. This is an Open Access article, distributed under the terms of the Creative Commons Attribution licence (http:// creativecommons.org/licenses/by/4.0/), which permits unrestricted re-use, distribution, and reproduction in any medium, provided the original work is properly cited. 
in preventing multiple chronic diseases, they may also contribute to improved health status of those already diagnosed with a chronic condition such as type 2 diabetes or osteoarthritis ${ }^{(12-15)}$

Health benefits of plant-based dietary patterns are not reserved exclusively to strict vegan/vegetarian diets. They can also be obtained from diets that not only remain plant heavy but also include modest intakes of fish, dairy consumption and occasional meat (e.g. pescatarian, flexitarian and Mediterranean diets) ${ }^{(16)}$. For instance, significantly lower odds of overweight/obesity, high TAG and high LDL were recently noted among semivegetarians compared with non-vegetarians in a South Asian sample ${ }^{(11)}$.

The benefits of plant-based diets extend beyond issues of human health as well; they have featured prominently, for example, in discussions regarding environmental sustainability. Plant-based diets have the potential to reduce impacts on the environment and contribute to improved food system resilience over time in multiple ways. A large body of research shows that meat-heavy diets require greater amounts of natural resources compared with plant-based diets. For example, on average, about $104.6 \mathrm{~kJ}$ $(25 \mathrm{kcal})$ of fossil fuel energy are required to produce $4.184 \mathrm{~kJ}$ ( $1 \mathrm{kcal}$ ) of animal protein, compared with $9 \cdot 2048 \mathrm{~kJ}(2 \cdot 2 \mathrm{kcal})$ of fossil fuel energy to produce $4 \cdot 184 \mathrm{~kJ}(1 \mathrm{kcal})$ of plant protein ${ }^{(17)}$. Beef production specifically is even more intensive, requiring forty times more energy ${ }^{(18)}$. One recent study also demonstrated that beef was the least efficient among commonly consumed protein foods when considering both global warming potential and protein quality simultaneously ${ }^{(19)}$. And Cordell et al. ${ }^{(20)}$ showed that meat-based diets required nearly three times the phosphorus as plant-based diets.

In addition to health and environmental motives, ethical concerns also drive the choice of plant-based diets ${ }^{(21,22)}$. One recent study demonstrated that empathy towards humans and animals was associated with positive attitudes towards plant-based dishes, in particular among vegetarians and flexitarians ${ }^{(23)}$. Other research has shown that vegetarians who were motivated by concerns for animals identified their dietary choices as a mechanism by which they could achieve more socially and morally oriented goals ${ }^{(24)}$.

Despite compelling benefits and a host of motivations to pursue plant-based diets, only $2-5 \%$ of American adults are following a vegetarian diet and only $0.5-2 \%$ consume no animal products at all ${ }^{(25-27)}$. Furthermore, the prevalence of vegetarians and vegans in the USA has not changed in the last 15 years ${ }^{(25)}$ despite the continuously growing market for plant-based products ${ }^{(1,2)}$. In fact, Americans generally fail to consume even the minimum recommendations for fruit and vegetable consumption, with only one in ten adults meeting recommendations ${ }^{(28)}$ based on the 2015-2020 Dietary Guidelines for Americans ${ }^{(29)}$.

Adopting and then sustaining a vegetarian or vegan diet can be challenging. The Humane Research Council found five times more former vegetarians/vegans than current vegetarians/vegans in the USA ${ }^{(30)}$. Moreover, former vegetarians/vegans do not sustain their diet for very long; approximately $34 \%$ followed their diet for 3 months, whereas $53 \%$ adhered to their diet for $<1$ year ${ }^{(30)}$. In addition, even those who were identified as vegetarian do not consistently adhere to their dietary goals; in a previous study using a representative sample of the USA, only a fifth of self-identified vegetarians were consistent in pursuing a strictly vegetarian $\operatorname{diet}^{(31)}$.

It is hard to overstate the difficulties for the adoption and adherence of vegetarian and vegan diets specifically. Change occurs - or fails to occur - in the context of a complex motivational system reflecting personal, social and environmental constraints and affordances ${ }^{(32-35)}$. Previous studies investigating the characteristics of individuals who decide to follow a vegetarian/vegan diet have revealed a host of motivational factors including a desire to enhance personal well-being and/or health, treatment of a specific health problem, ethical concerns (e.g. animal welfare and environment protection), taste preferences, religious beliefs and social/ family motives ${ }^{(27,30,36-39)}$. Nonetheless, much less is known about the control mechanisms that allow individuals to sustain a vegetarian/vegan diet in the face of numerous obstacles.

The desire to initiate and sustain a plant-based diet can be seen as a goal motivated by any of the above reasons. Goals are defined as internal representations of desired states that compel the individual to decrease the discrepancy between a desired state and the current state ${ }^{(40)}$. After a person has determined the goals to be pursued and their respective success criteria, the process of goal striving begins ${ }^{(41)}$. Successful goal striving will depend on overcoming two primary self-regulatory challenges: the planning and execution of actions that promote goal achievement and the protection of valued goals from disruption given the likely presence of competing goals ${ }^{(41)}$.

The present study included examination of how people think about, appraise or cognitively frame the process of goal striving towards a plant-based diet in an attempt to capture the 'internal workings' or the 'how' of the motivational system. A major focus was on 'goal representation' as elaborated in Ford's living systems model of human self-directedness ${ }^{(42)}$. Ford's model postulates a goal-based self-regulating system that comprises a set of basic organising functions. The directive or feedforward function taps the thoughts or beliefs that presumably activate the individual to move towards a particular goal or end state - this function establishes what the individual desires. The regulatory function serves as a 'comparator' mechanism, evaluating how well the current state matches the desired state. The control function institutes strategies to correct discrepancies between the current and desired state. Finally, the arousal function provides the emotional activation for goal-directed behaviour. 
Thus, following Ford's model, the planning, regulation and execution of behaviour that support the goal of adhering to a plant-based diet were examined. In addition, because ethical/moral motivations have been shown to be common among those following a vegan/vegetarian $\operatorname{diet}^{(21-24,36-39)}$, we examined the role of type of motivations on the likelihood of adhering to a plant-based diet, alone and in conjunction with the elements of the self-regulatory system outlined above.

In sum, the study investigated the process of successful striving towards the adherence of a plant-based diet using a goal-systems perspective that captures the internal workings of the motivational system. Hypotheses were as follows:

H1: Individuals who successfully adhere to a plant-based diet (Adherents) will show a more effective self-regulatory system compared with individuals who struggle to adhere to a plant-based diet (Non-adherents). Specifically, it was expected that adherents would display (1) significantly higher levels of value, self-efficacy, self-monitoring, social comparison, planning, self-reward and positive affect and (2) significantly lower levels of self-criticism and negative affect, compared with non-adherents.

H2: Type of motivations will significantly predict adherence to a plant-based diet.

H3: Elements of the self-regulatory system, such as value, self-efficacy and planning, will predict adherence to a plant-based diet controlling for motivations.

\section{Methods}

\section{Participants}

Participants in the present study were recruited from a large online survey conducted with students enrolled in an Introduction to Psychology course in a university of the Southwest of the United States. The study was approved by the university's Institutional Review Board. Students received research credits for their Introduction to Psychology course in compensation for their participation in the study. This original sample comprised 1501 students with a mean age of 19.24 years (SD 2.55). Fiftyfour percentage were female; $54 \%$ were White, $4 \%$ African American, $18 \%$ Hispanic/Latino, 1\% Native American, $10 \%$ East Asian, 3\% South Asian, 4\% Asian American and 6\% other background.

In the initial screening survey, students were asked about their current eating preferences with a multiplechoice question. The options were: (1) vegan for 12 months or longer, (2) vegetarian for 12 months or longer, (3) pescatarian for 12 months or longer, (4) currently striving to change eating habits in order to achieve a vegan, vegetarian or pescatarian diet, but not always successful, (5) past unsuccessful attempts to achieve a pescatarian, vegetarian or vegan diet and currently having no desire to try again and (6) never tried to achieve a vegan, vegetarian or pescatarian diet with no desire to do so. A standard definition for each type of diet was provided (e.g. 'I would describe myself as vegan. I have not eaten meat, seafood, poultry, dairy, or eggs for 12 months or longer.').

Students who described themselves as vegan, vegetarian or pescatarian for 12 months or longer were designated to the Adherents group ( $n 91 ; 6 \cdot 1 \%$ ), whereas those who described themselves as currently trying to adhere to a plant-based diet but were not always successful were designated to the Non-adherents group ( $n$ 178; 11.9\%). Students from these two groups were recruited via email to participate in a follow-up survey. A total of thirty-three students from the Adherent group and sixty-three from the Non-adherent group provided informed consent and completed the follow-up survey. No statistical differences in demographic characteristics were found between those students who agreed to participate in the follow-up survey and those who did not agree (all $P>0 \cdot 11$ ).

\section{Follow-up survey}

The follow-up survey was implemented through Qualtrics and included questions about demographic background and the variables under investigation. Completion of the survey took approximately 8-10 min. Demographic questions included age, sex, race/ethnic and religious affiliation, political views and socio-economic status (please see Table 1).

Goal representation during the process of goal striving towards a plant-based diet was assessed with the Goal Systems Assessment Battery (GSAB) ${ }^{(43)}$, a thirty-six-item self-report questionnaire based upon Ford's living systems model of human self-directedness ${ }^{(42)}$ that taps the four previously described functions of a self-regulating system. These functions are measured via nine subscales that include value and self-efficacy - directive or feedforward function; social comparison and self-monitoring - regulatory function; planning/stimulus control, self-reward and selfcriticism - control function; and positive affect and negative affect - arousal function.

An example of an item for the self-monitoring subscale would be: 'I keep track of my overall progress toward this goal', whereas an example of an item for the social comparison subscale would be 'I evaluate my progress toward this goal in comparison to how well other people are doing in pursuing it'. Each item is answered in a Likert scale ranging from $0=$ not at all to $4=$ extremely. Subscale scores are derived from the sum of the items associated with each particular subscale; scores can range from 0 to 16. Higher scores represent a higher degree of the concept under study. Participants in the present study were instructed to respond to each GSAB item in relation to their goal of achieving a plant-based diet (either vegan, vegetarian or pescatarian). 
Table 1 Demographic characteristics of non-adherents and adherents to a plant-based diet $(n 96)$

\begin{tabular}{|c|c|c|c|}
\hline & $\begin{array}{l}\text { Non-adherents } \\
(n 63)\end{array}$ & $\begin{array}{l}\text { Adherents } \\
\quad(n 33)\end{array}$ & $P$ value \\
\hline \multicolumn{4}{|l|}{ Age (years) } \\
\hline Median & 18 & 18 & \multirow[t]{2}{*}{0.993} \\
\hline Interquartile range & $18-19$ & $18-19.5$ & \\
\hline \multicolumn{4}{|l|}{ Sex $(\%)$} \\
\hline Male & $30 \cdot 6$ & $30 \cdot 3$ & 0.972 \\
\hline \multicolumn{4}{|l|}{ Ethnicity (\%) } \\
\hline Caucasian & $46 \cdot 0$ & $51 \cdot 5$ & \multirow[t]{5}{*}{0.701} \\
\hline African-American & 7.9 & $3 \cdot 0$ & \\
\hline Hispanic & 17.5 & $12 \cdot 1$ & \\
\hline Native American & 1.6 & 0.0 & \\
\hline Other & $27 \cdot 0$ & $33 \cdot 3$ & \\
\hline \multicolumn{4}{|l|}{ Religious affiliation (\%) } \\
\hline Atheist & 11.5 & 9.1 & \multirow[t]{6}{*}{0.539} \\
\hline Agnostic & 11.5 & $15 \cdot 2$ & \\
\hline Catholic & $14 \cdot 8$ & $9 \cdot \overline{1}$ & \\
\hline $\begin{array}{l}\text { Christian, but not } \\
\text { Catholic }\end{array}$ & $27 \cdot 9$ & $18 \cdot 2$ & \\
\hline $\begin{array}{l}\text { Spiritual, but not } \\
\text { religious }\end{array}$ & $21 \cdot 3$ & $21 \cdot 2$ & \\
\hline Other & $13 \cdot 1$ & $27 \cdot 3$ & \\
\hline \multicolumn{4}{|l|}{ Political views (\%) } \\
\hline Democrat & $58 \cdot 1$ & 51.5 & \multirow[t]{3}{*}{0.808} \\
\hline Republican & 14.5 & $15 \cdot 2$ & \\
\hline Other & 27.4 & 33.3 & \\
\hline \multicolumn{4}{|c|}{ Socio-economic status (\%) } \\
\hline Upper class & $6 \cdot 3$ & $9 \cdot 1$ & \multirow[t]{6}{*}{0.499} \\
\hline Upper-middle class & $30 \cdot 2$ & $42 \cdot 4$ & \\
\hline Middle class & $42 . \overline{9}$ & $30 \cdot 3$ & \\
\hline Lower-middle class & $14 \cdot 3$ & $18 \cdot 2$ & \\
\hline Working class & $4 \cdot 8$ & 0.0 & \\
\hline Other & 1.6 & 0.0 & \\
\hline
\end{tabular}

${ }^{*}$ Age is presented as medians and interquartile ranges due to non-normality. $P$ value represents results from $\chi^{2}$ analyses for categorical data and Mann-Whitney $U$ test for continuous data.

The GSAB has been used in a variety of research settings and populations, possesses acceptable psychometric properties including good retest reliability, low social desirability response bias and ample evidence of predictive validity ${ }^{(43)}$. In addition, the factor structure of the instrument has been previously confirmed (comparative fit index $=0.91-0.99)^{(43)}$. Research has shown that the GSAB relates in a statistically significant manner to mental health functioning, exercise participation, BMI and pain experience ${ }^{(43-48)}$.

Lastly, students were asked to indicate their motivations for their current dietary pattern from a list of thirteen possible motivations. Students were free to select multiple motivations and were also provided an option to enter 'other' motivation not included in the list (please see Table 4). This list of motivations was created based on findings from previous research ${ }^{(21-24,36-39)}$.

\section{Statistical analyses}

Statistical analyses were performed with the Statistical Package for the Social Sciences version 24 (IBM). Preliminary $\chi^{2}$ and Mann-Whitney $U$ test analyses were conducted for categorical and continuous variables, respectively. No significant demographic differences between groups were found (see results section below), and hence demographics were not included in subsequent analyses.

To test our primary hypothesis (H1) that Adherents would show a more effective self-regulatory system compared with Non-adherents, a discriminant function analysis using the nine GSAB subscales was conducted to examine if groups can be differentiated by a unique combination of self-regulatory scores. Initial data screening indicated no missing data and no violations of statistical assumptions, except for a few univariate outliers; these outliers, which were determined to potentially bias populations parameters, were removed as suggested by the literature ${ }^{(49)}$, resulting in a total sample of eighty-nine participants whose data were used for this analysis.

To test our second hypothesis (H2), we conducted a logistic regression analysis to assess whether a variety of motivations for a plant-based diet predicted the likelihood of successfully adhering to a plant-based diet goal.

Finally, to test our third hypothesis (H3), we conducted a hierarchical logistic regression to assess whether elements of the self-regulatory system predict the likelihood of adhering to a plant-based diet when controlling for motivations. Significance was set at $\alpha<0.05$.

\section{Results}

$\chi^{2}$ analyses revealed no significant differences between groups for sex, $\chi^{2}(1, n 95)=0.001$ and $P=0.97$; religion, $\chi^{2}(5, n 94)=4.07$ and $P=0.53$; race/ethnic affiliation, $\chi^{2}(4, n 96)=2 \cdot 18$ and $P=0.70$; political views, $\chi^{2}(2, n 95)=$ 0.42 and $P=0.80$; or socio-economic status, $\chi^{2}(5, n 96)=4.36$ and $P=0.49$. Similarly, the Mann-Whitney $U$ test indicated no difference in age between groups; $U=1038.5$, $z=-0.009$, and $P=0.99$.

The discriminant function calculated based on the combination of the GSAB scores significantly differentiated adherents $v$. non-adherents and accounted for $34.7 \%$ of the between-group variance, $\chi^{2}(9)=35 \cdot 20$, $P<0.000$ (please see Table 2 for GSAB scores). It correctly classified $71.4 \%$ of the adherents and $80.3 \%$ of the non-adherents. Value, self-efficacy, planning/stimulus control and positive affect were positively correlated with the discriminant function, whereas self-monitoring and self-criticism were negatively correlated. Nonetheless, only value, self-efficacy, planning/stimulus control and positive affect showed correlations higher than $0 \cdot 33$, which is considered acceptable for inclusion in the discriminant function ${ }^{(49)}$. Social comparison, self-reward and negative affect did not significantly contribute to the distinction between groups. Please refer to Table 3.

The logistic regression analysis assessing motivations as predictors on the likelihood of adhering to a plantbased diet indicated that the model was significant, 
Goal-systems and plant-based eating

Table 2 Participants' scores on the different subscales of the Goal Systems Assessment Battery (GSAB) instrument

\begin{tabular}{|c|c|c|c|c|c|c|}
\hline \multirow[b]{2}{*}{ Subscale } & \multicolumn{3}{|c|}{ Non-adherents } & \multicolumn{3}{|c|}{ Adherents } \\
\hline & Median & & Interquartile range & Median & & Interquartile range \\
\hline Value & 12 & & $8-14$ & 14.5 & & $11-16$ \\
\hline Self-efficacy & 11 & & $9-13$ & 14 & & $11-15$ \\
\hline Social comparison & 6 & & $2-9$ & 6 & & $1 \cdot 5-9$ \\
\hline \multicolumn{7}{|l|}{ Self-monitoring } \\
\hline Mean & & 8.93 & & & $10 \cdot 18$ & \\
\hline SD & & $3 \cdot 11$ & & & $2 \cdot 55$ & \\
\hline \multicolumn{7}{|l|}{ Planning } \\
\hline Mean & & $8 \cdot 25$ & & & $10 \cdot 96$ & \\
\hline SD & & 3.25 & & & $2 \cdot 60$ & \\
\hline Self-criticism & 7 & & $3-10$ & 5 & & $2-8$ \\
\hline \multicolumn{7}{|l|}{ Self-reward } \\
\hline Mean & & $8 \cdot 17$ & & & $7 \cdot 27$ & \\
\hline SD & & 3.90 & & & $4 \cdot 32$ & \\
\hline Positive affect & 10 & & $6-12$ & 12 & & $8 \cdot 5-13.5$ \\
\hline Negative affect & 4 & & $1-7$ & 4 & & $2.5-7.5$ \\
\hline
\end{tabular}

*Means and standard deviations are presented for normally distributed data. Medians and interquartile ranges are presented for non-normally distributed data. Total range of scores for all subscales above was 0-16.

Table 3 Standardized discriminant function coefficients and structure matrix correlations in the discriminant function analysis using the Goal Systems Assessment Battery (GSAB) subscales to differentiate between adherents and non-adherents to a plant-based diet

\begin{tabular}{lcccc}
\hline Subscale & Coefficient & $R$ & $r^{2}(\%)$ & $P$ value \\
\hline Value & 0.173 & 0.414 & 17.13 & 0.006 \\
Self-efficacy & 0.112 & 0.361 & 13.03 & 0.016 \\
Social comparison & -0.002 & 0.312 & 09.73 & 0.989 \\
Self-monitoring & -0.164 & -0.002 & 00.00 & 0.037 \\
Planning & 0.786 & 0.602 & 36.24 & 0.000 \\
Self-criticism & -1.028 & -0.306 & 09.36 & 0.040 \\
Self-reward & -0.366 & -0.071 & 00.50 & 0.630 \\
Positive affect & 0.039 & 0.375 & 14.06 & 0.012 \\
Negative affect & 0.913 & 0.122 & 01.48 & 0.410 \\
\hline
\end{tabular}

Significant $P$ values are bolded.

$\chi^{2}(13)=42 \cdot 03, P<0 \cdot 000$. The Hosmer and Lemeshow test indicated that the model described the data well $\left(\chi^{2}(8)=5.92, P=0.66\right)$ correctly classifying $72.7 \%$ of adherents and $88.9 \%$ of non-adherents, whereas the Nagelkerke $R^{2}$ indicated that the model explained $49.0 \%$ of the variance.

The only significant individual predictors were 'To maintain and/or improve my health,' 'To manage or treat a medical condition' and 'To align with my ethical beliefs'. Participants who successfully adhered to a plant-based diet were seventeen times more likely to report 'To manage or treat a medical condition' as motivation and almost seven times more likely to report 'To align with my ethical beliefs' as motivation compared with nonadherents. On the contrary, participants who successfully adhered to a plant-based diet were $94 \%$ less likely to report 'To maintain and/or improve my health' as motivation compared with non-adherents. (Table 4)

Only significant variables from the previous two analyses were included in the final hierarchical logistic regression analysis. Results indicated that model 2 assessing the significance of the self-regulatory system on predicting adherence to a plant-based diet controlling for motivations was significant, $\chi^{2}(7)=45.09, P<0.000$. The Hosmer and Lemeshow test indicated that model 2 adequately described the data $\left(\chi^{2}(8)=14.63, P=0.07\right)$ correctly classifying $73.3 \%$ of adherents and $88.9 \%$ of non-adherents. The Nagelkerke $R^{2}$ indicated that explained variance increased from $39.5 \%$ in model 1 (motivations only) to $53.7 \%$ in model 2 (motivations + elements from self-regulatory system). However, the only significant predictor from the self-regulatory system was planning; those that scored higher on planning had a $37 \%$ higher likelihood to adhere to a plant-based diet. Please refer to Table 5 .

\section{Discussion}

The main purpose of this study was to examine factors related to successful striving towards the adherence of a plant-based diet using a goal-systems perspective. 
Table 4 Results of logistic regression analyses using motivations for current eating habits to predict the likelihood of successfully adhering to a plant-based diet

\begin{tabular}{lrrr}
\hline & Exp $(\mathrm{B})$ & \multicolumn{1}{c}{$95 \% \mathrm{Cl}$} & $P$ value \\
\hline To maintain and/or improve my health & $\mathbf{0 . 0 5}$ & $\mathbf{0 . 0 0 , 0 . 4 1}$ & $\mathbf{0 . 0 0 4}$ \\
To manage or treat a medical condition & $\mathbf{1 7 . 4 1}$ & $\mathbf{2 . 5 8 , 1 1 7 . 1 6}$ & $\mathbf{0 . 0 0 3}$ \\
To align with my ethical beliefs & $\mathbf{6 . 8 8}$ & $\mathbf{1 . 8 2 , 2 5 . 9 5}$ & $\mathbf{0 . 0 0 4}$ \\
To adhere to my religious beliefs & 3.50 & $0.27,45.12$ & 0.336 \\
To have the best tasting food & 0.30 & $0.04,1.99$ & 0.216 \\
To maximise my pleasure or enjoyment while eating & 2.18 & $0.38,12.35$ & 0.375 \\
To fit within my budget & 0.60 & $0.14,2.60$ & 0.501 \\
To support my local farmers and/or community & 1.64 & $0.36,7.32$ & 0.514 \\
To support sustainable practices & 1.94 & $0.48,7.78$ & 0.349 \\
To act like the person I want to be & 2.55 & $0.73,8.89$ & 0.139 \\
To conform with societal expectations & 0.56 & $0.04,7.20$ & 0.663 \\
To be true to myself and live in accordance with who I am & 1.46 & $0.30,7.13$ & 0.638 \\
\hline
\end{tabular}

Significant $P$ values are bolded.

Table 5 Results of hierarchical logistic regression analysis predicting adherence to a plant-based diet from motivations and elements from the self-regulatory system

\begin{tabular}{|c|c|c|c|c|c|c|}
\hline \multirow[b]{2}{*}{ Variable } & \multicolumn{3}{|c|}{ Model 1} & \multicolumn{3}{|c|}{ Model 2} \\
\hline & B & $\operatorname{Exp}(B)$ & $95 \% \mathrm{Cl}$ & B & $\operatorname{Exp}(B)$ & $95 \% \mathrm{Cl}$ \\
\hline Constant & 0.15 & $1 \cdot 16$ & & $-3 \cdot 72$ & $0.024^{\star}$ & \\
\hline To maintain and/or improve my health & -2.43 & $0.088^{* *}$ & $0.01,0.41$ & -2.97 & $0.051^{* *}$ & $0.00,0.31$ \\
\hline To manage or treat a medical condition & 2.39 & $10 \cdot 97^{\star \star}$ & $2 \cdot 28,52 \cdot 65$ & $2 \cdot 38$ & $10 \cdot 81^{*}$ & $1 \cdot 76,66 \cdot 15$ \\
\hline To align with my ethical beliefs & $2 \cdot 35$ & $10 \cdot 49^{\star *}$ & $3 \cdot 17,34 \cdot 66$ & $2 \cdot 27$ & $9 \cdot 76^{\star *}$ & $2.44,39.02$ \\
\hline Value & & & & 0.01 & 1.01 & $0.76,1.35$ \\
\hline Self-efficacy & & & & 0.12 & $1 \cdot 13$ & $0.84,1.52$ \\
\hline Planning & & & & 0.31 & $1 \cdot 37^{\star}$ & $1.06,1.78$ \\
\hline Positive affect & & & & -0.04 & 0.95 & $0.76,1.19$ \\
\hline
\end{tabular}

${ }^{\star} P<0.05,{ }^{\star \star} P<0.01$

We hypothesised that individuals who successfully adhered to a plant-based diet would show a more effective selfregulatory system compared with individuals who struggled to adhere to a plant-based diet. The results partially supported our hypothesis. High levels of value, self-efficacy, planning/ stimulus control and positive affect significantly contributed to the distinction between adherents and non-adherents; among these predictors, planning showed the highest correlation and explained more than $36 \%$ of the difference between groups. These results reflect prior research related to health behaviours in college students, in which goal regulatory thinking was also strongly supportive of exercise goals among regular exercisers compared with irregular exercisers, for whom other life goals competed with attempts to exercise ${ }^{(44)}$. Other applications of goal regulatory thinking have been studied in this population in relation to academic performance, in which certain types of academic goals were associated with better or worse exam scores, mediated by self-regulatory skills ${ }^{(50)}$.

Thus, in the process of goal representation, the control function as represented by planning/stimulus control appears to have the greatest relevance among young adults striving to maintain a plant-based diet. Accordingly, careful and strategic planning may allow for a successful adjustment of inconsistencies between current and desired states. Social psychological theory postulates that the planning of actions promoting goal achievement is one of the primary self-regulatory challenges to overcome for successful goal striving ${ }^{(41)}$. In addition, planning is considered the key element that connects behavioural intentions and actions ${ }^{(44)}$. The results from this study support these concepts and highlight the important role of planning specifically for successful adherence to a plant-based diet.

This study also investigated the significance of motivations for predicting the likelihood of successfully adhering to a plant-based diet goal. We found that health and ethical motivations were significant predictors for adherence, which is in line with the current literature. Health benefits and ethical concerns are the most commonly cited reasons for starting a vegan $\operatorname{diet}^{(37)}$. However, we found that 'To maintain and/or improve my health' as a motivation was in fact predictive of a lesser likelihood of adhering to a plant-based diet. Similarly, the Humane Research Council found that former vegetarians often reported health concerns as the only reason for starting a plant-based diet $^{(30)}$. On the contrary, the motivation to treat a medical condition significantly predicted the likelihood of successfully adhering 
to this type of dietary goal. Our study thus adds to the literature by making the distinction between following a plant-based diet for improving health in general $v$. caring for a specific medical condition, the latter appearing to have a stronger impact on successful goal striving.

While the medical community and general public may acknowledge the advantages of following a plant-based diet for treating a variety of medical conditions ${ }^{(15)}$, choosing to completely or partially eliminate animal products from one's diet because of ethical reasons is worthy of further discussion. In a previous study, individuals who originally became vegetarian for ethical reasons had been vegetarian for significantly longer and showed a higher conviction compared with those who became vegetarian for health reasons ${ }^{(51)}$. Conversely, lower justice concerns (animal protection, environmental concerns and ending world hunger) have been found to fully mediate the relationship between conservatism and lapsing to meat-eating among individuals initially adopting a vegan/vegetarian diet ${ }^{(52)}$.

It has been suggested that following a plant-based diet for ethical reasons involves values for which food is another form of expression, and therefore, a plant-based diet is not the ultimate goal in itself but the means to attain a larger overall goal that derives from these values and a strong personal identity ${ }^{(39)}$. Thus, for followers of a plantbased diet, food is not just a source of nutrition but also perhaps reflective of who a person is and who that person would like to be ${ }^{(53)}$. Following a plant-based diet can then be seen as an element of an overall lifestyle framework that provides individuals with purpose and personal satisfaction. Related research offers some insights along these lines. Studies exploring the relation between Goldberg's Big Five personality traits and dietary intake, for example, suggest that aspects that help to define one's personality may influence food choices. One recent review noted the trait of conscientiousness as being particularly relevant in relation to health behaviours, specifically healthy eating ${ }^{(54)}$. Another large study in obese individuals identified conscientiousness, among other personality traits, as being related to restrained eating, which could be important in weight regulation over time ${ }^{(55)}$.

The results from our hierarchical logistic regression analysis also showed an increase from 39.5 to $53.7 \%$ of explained variance when planning was added to motivations as predictors of adherence to a plant-based diet. Thus, the results from this study indicate that an individual must develop a coherent self-regulatory system that facilitates the process of striving towards a plant-based diet goal, in which planning appears to be essential. Planning is divided into two distinct constructs: action planning (the process of specifying the when, where and how to act) and coping planning (the mental representation of potential risk situations and appropriate coping responses). Action planning has been found more impactful in the early implementation of behaviour change, whereas coping planning has been found more impactful during behaviour maintenance ${ }^{(56)}$. Prior research has demonstrated that among the barriers for adopting a plant-based diet, it is the perception that it is difficult and time-consuming to prepare vegetarian-style foods, not knowing what to eat instead of meat, and not wanting to be stereotyped negatively ${ }^{(57)}$. Hence, in the context of striving towards a plant-based diet, action planning may involve learning how to cook vegetarian-style foods, preparing a shopping list and developing a weekly meal plan, whereas coping planning may entail mentally preparing for adverse social situations by appealing to personal values and convictions. Future research should focus not only on motivations for adopting a plant-based diet but also on strategies for effective planning in order to achieve a sustained dietary behaviour change.

\section{Limitations}

Some of the limitations of this study include a relatively small sample size and the self-report nature of eating preferences. Future studies should corroborate adherence to a plant-based diet with detailed dietary logs and/or biological markers with larger samples. Future studies should also include participants that follow other forms of plant-based diets such as flexitarians/semi-vegetarians. In addition, our list of motivations to follow a plant-based diet, though reflective of the literature, is by no means exhaustive; other motivations may be significant and worthy of future investigation. Similarly, other psychological factors could be important in relation to interest in, and adhering to, plant-based diets that were not evaluated in this study. For example, conscientiousness as defined in Goldberg's 'Big Five' personality traits could further explain the ways in which individuals' motivations and sense of identity relate to food choices and dietary patterns. Lastly, the results of this study should be corroborated with different populations such as full-time working adults and individuals with varied demographic characteristics; the process of self-regulation and/or motivations may differ as work/ family responsibilities change, whereas motivations, and in particular ethical beliefs, may be stronger among certain ethnic/religious groups.

\section{Implications for research and practice}

Ethical beliefs and planning seem to be key elements for the successful implementation and maintenance of a plant-based diet. Plant-based diets represent important opportunities for improved health and environmental impact simultaneously. As such, future research as well as public health campaigns designed to promote more plant-heavy diets could potentially be more impactful if they leverage multiple motivators including ethical beliefs and sustainability concerns. Further, public health campaigns could improve success by incorporating guidelines and other tools focused on effective planning of both 
the implementation of plant-based diets as well as their maintenance over time and in multiple social situations.

\section{Acknowledgements}

Acknowledgements: None. Financial support: This research did not receive any specific grant from funding agencies in the public, commercial or not-for-profit sectors. Conflict of interest: None. Authorship: M.V. contributed to study design, conducted analyses and lead manuscript preparation; L.S.R. contributed to study design, analyses and manuscript preparation; P.K. contributed to study design and edited the manuscript; K.S. contributed to participant recruitment and data collection; A.B. contributed to study design and manuscript editing; S.L. contributed to study design and editing; C.M.W. oversaw the project, contributed to study design and analyses and contributed to manuscript preparation and editing. Ethics of human subject participation: This study was conducted according to the guidelines laid down in the Declaration of Helsinki, and all procedures involving study participants were approved by the Arizona State University Institutional Review Board. Electronic consent was obtained: after reading an online consent form, participants consented prior to starting the survey by clicking an agreement button at its beginning.

\section{References}

1. Nielsen (2017) Plant-based proteins are gaining dollar share among North Americans. Available at online https://www. nielsen.com/us/en/insights/news/2017/plant-based-proteinsare-gaining-dollar-share-among-north-americans.html (accessed August 2019).

2. Nielsen (2018) Plant-based food options are sprouting growth for retailers. Available at https://www.nielsen.com/ us/en/insights/news/2018/plant-based-food-options-aresprouting-growth-for-retailers.html (accessed August 2019).

3. Lynch H, Johnston C \& Wharton CM (2018) Plant-based diets: Considerations for environmental impact, protein quality, and exercise performance. Nutrients. Published online: 1 December 2018. doi: 10.3390/nu10121841.

4. Derbyshire E (2017) Flexitarian diets and health: a review of the evidence-based literature. Front Nutr. Published online: 6 January 2017. doi: 10.3389/fnut.2016.000552017.

5. Barnard ND, Levin SM \& Yokoyama Y (2015) A systematic review and meta-analysis of changes in body weight in clinical trials of vegetarian diets. J Acad Nutr Diet 115, 954-969.

6. Huang RY, Huang CC, Hu FB et al. (2016) Vegetarian diets and weight reduction: a meta-analysis of randomized controlled trials. J Gen Intern Med 31, 109-116.

7. Yokoyama Y, Nishimura K, Barnard ND et al (2014) Vegetarian diets and blood pressure: a meta-analysis. JAMA, Intern Med 174, 577-587.

8. Wang F, Zheng J, Yang B et al. (2015) Effects of vegetarian diets on blood lipids: a systematic review and meta- analysis of randomized controlled trials. J Am Heart Assoc. Published online: 27 October 2015. doi: 10.1161/JAHA.115.002408.

9. Dinu M, Abbate R, Gensini GF et al (2017) Vegetarian, vegan diets and multiple health outcomes: a systematic review with meta-analysis of observational studies. Crit Rev Food Sci Nutr 57, 3640-3649.
10. Orlich MJ \& Fraser GE (2014) Vegetarian diets in the Adventist Health Study 2: a review of initial published findings. Am J Clin Nutr 100, 353S-358S.

11. Jacks LM, Kapoor D, Singh K et al (2016) Vegetarianism and cardiometabolic disease risk factors: differences between South Asian and US adults. Nutrition 32, 975-984.

12. Barnard ND, Cohen J, Jenkins DJ et al (2006) A low-fat vegan diet improves glycemic control and cardiovascular risk factors in a randomized clinical trial in individuals with Type 2 diabetes. Diabetes Care 29, 1777-1783.

13. McMacken M \& Shah S (2017) A plant-based diet for the prevention and treatment of type 2 diabetes. J Geriatr Cardiol 14, 342-354.

14. Clinton CM, O'Brien S, Law J, et al. (2015) Whole-foods, plant-based diet alleviates the symptoms of osteoarthritis. Arthritis. Published online: 28 February 2015. doi: 10.1155/ 2015/708152.

15. Tuso PJ, Ismail MH, Ha BP et al (2013) Nutritional update for physicians: plant-based diets. Perm J 17, 61-66.

16. McEvoy CT, Temple N \& Woodside JV (2012) Vegetarian diets, low-meat diets and health: a review. Public Health Nutr 15, 2287-2294.

17. Pimentel D \& Pimentel M (2003) Sustainability of meat-based and plant-based diets and the environment. Am J Clin Nutr 78, 660S-663S.

18. Sabate J \& Soret S (2014) Sustainability of plant-based diets: back to the future. Am J Clin Nutr 100, 476S-482S.

19. Berardy A, Johston C, Plukis A, et al. (2019) Integrating protein quality and quantity with environmental impacts in life cycle assessment. Sustainability. Published online: 14 May 2019. doi: 10.3390/su11102747.

20. Cordell D, Drangert JO \& White S (2009) The story of phosphorus: global food security and food for thought. Global Environ Chang 19, 292-305.

21. Fox N, Ward K (2008) Health, ethics, and environment: a qualitative study of vegetarian motivations. Apptetite $\mathbf{5 0}$, 422-429.

22. Rosenfeld D \& Tomiyama AJ (2019) How proximal are pescatarians to vegetarians? An investigation of dietary identity, motivation, and attitudes toward animals. J Health Psych. Published online: 10 April 2019. doi: 10.1359105319842933.

23. Cliceri D, Spinelli S, Dinnella C et al (2018) The influence of psychological traits, beliefs and taste responsiveness on implicit attitudes toward plant- and animal-based dishes among vegetarians, flexitarians and omnivores. Food Qual Prefer 68, 276-291.

24. Rosenfeld D (2019) Why some choose the vegetarian option: are all ethical motivations the same? Motiv Emot 43, 400-411.

25. Vegetarian times (2019) Vegetarianism in America. Available at https://www.vegetariantimes.com/uncategorized/ vegetarianism-in-america (accessed March 2019).

26. Gallup (2018) Snapshot: Few Americans vegetarian or vegan. Available at https://news.gallup.com/poll/238328/snapshotfew-americans-vegetarian-vegan.aspx (accessed March 2019).

27. Cramer H, Kessler CS, Sundberg Tet al (2017) Characteristics of Americans choosing vegetarian and vegan diets for health reasons. J Nutr Educ Behav 49, 561-567.

28. Lee-Kwan SH, Moore LV, Blanck HM, et al (2017) Disparities in state-specific adult fruit and vegetable consumption United Stated, 2015. MMWR 66, 1241-1247.

29. U.S. Department of Health and Human Services \& U.S. Department of Agriculture (2015) 2015-2020 Dietary Guidelines for Americans, 8th ed. Available at https://health. gov/dietaryguidelines/2015/guidelines/ (accessed July 2019).

30. Humane Research Council (2015) Study of current and former vegetarians and vegans. Available at https://faunalytics. org/wp-content/uploads/2015/06/Faunalytics_Current-FormerVegetarians_Full-Report.pdf (accessed March 2019). 
31. Dietz T, Frisch AS, Kalof L et al (1995) Values and vegetarianism: an exploratory analysis. Rural Sociol 60, 533-542.

32. Karoly P (2012) Self-regulation. In Cognitive Behavior Therapy: Core Principles for Practice, pp. 183-213 [O'Donohue WT \& Fishers JE, editors]. Hoboken, NJ: Wiley.

33. Karoly P \& Anderson CW (2000) The long and short of psychological change: Toward a goal-centered understanding of treatment durability and adaptive success. In Handbook of Psychological Change: Psychotherapy Processes for the 21st Century, pp. 154-176 [Snyder CR \& Ingram RE, editors]. New York, NY: Wiley.

34. Karoly P (1982) Self-Management and Behavior Change: From Theory to Practice. New York, NY: Pergamon Press.

35. Spencer L, Wharton CM \& Adams T (2007) The Transtheoretical model as applied to dietary behaviour and outcomes. Nut Res Rev 20, 46-73.

36. Janssen M, Busch C, Rödiger M et al (2016) Motives of consumers following a vegan diet and their attitudes towards animal agriculture. Appetite 105, 643-651.

37. Radnitz R, Beezhold B \& DiMatteo J (2015) Investigation of lifestyle choices of individuals following a vegan diet for health and ethical reasons. Appetite 90, 31-36.

38. Rosenfeld DL \& Burrow AL (2017) The unified model of vegetarian identity: a conceptual framework for understanding plant-based good choices. Appetite 112, 78-95.

39. Rosenfeld DL \& Burrow AL (2017) Vegetarian on purpose: understanding the motivations of plant-based eating. Appetite 116, 456-463.

40. Austin JT \& Vancouver JB (1996) Goal constructs in psychology: structure, process, and content. Psychol Bull 120, 338-375.

41. Mann T, De Ridder D \& Fujita K (2013) Self-regulation of health behavior: social psychological approaches to goal setting and goal striving. Health Psychol 42, 487-498.

42. Ford DH (1987) Humans as Self-Constructing Living Systems: A Developmental Perspective on Behavior and Personality. Hillsdale, NJ: Erlbaum.

43. Karoly P \& Ruehlman L (1995) Goal cognition and its clinical implications: development and preliminary validation of four motivational assessment instruments. Assessment $\mathbf{2}$, 113-129.

44. Karoly P, Ruehlman LS, Okun MA et al (2005) Perceived selfregulation of exercise goals and interfering goals among regular and irregular exercisers: a life space analysis. Psychol Sport Exerc 6, 427-442.
45. Lutz RS, Karoly P \& Okun MA (2008) The why and the how of goal pursuit: self-determination, goal process cognition, and participation health education research in physical exercise. Psychol Sport Exerc 9, 559-575.

46. Weiland S (2015) Genetic influences on executive function and self-regulation of body mass index. PhD Thesis, University of Arizona. Available at https://repository.arizona. edu/handle/10150/594388 (accessed August 2019).

47. Karoly P \& Ruehlman LS (1996) Motivational implications of pain: chronicity, psychological distress, and work goal construal in a national sample of adults. Health Psychol 15 , 383-390.

48. Karoly P, Okun MA, Ruehlman LS, et al (2008) The impact of goal cognition and pain severity on disability and depression in adults with chronic pain: An examination of direct effects and mediated effects via pain-induced fear. Cognit Ther Res 32, 418-433.

49. Tabachnick BG \& Fidell LS (2012) Using Multivariate Statistics, 6th ed. Boston, MA: Pearson Education.

50. Okun MA, Fairholme C, Karoly P, et al (2006) Academic goals, goal process cognition, and exam performance among college students. Learn Individ Differ 16, 255-265.

51. Hoffman SR, Stallings SF, Bessinger RC et al (2013) Differences between health and ethical vegetarians. Strength of conviction, nutrition knowledge, dietary restriction, and duration of adherence. Appetite 65, 139-144.

52. Hodson G \& Earle M (2018) Conservatism predicts lapses from vegetarian/vegan diets to meat consumption (through lower social justice concerns and social support). Appetite 120, 75-81.

53. Beverland MB (2014) Sustainable eating: mainstreaming plantbased diets in developed economies. J Macromarketing 34, 369-382.

54. Lunn TE, Nowson CA, Worsley A, et al (2014) Does personality affect dietary intake? Nutrition 30, 403-409.

55. Elfhag K \& Morey LC (2008) Personality traits and eating behavior in the obese: poor self-control in emotional and external eating but personality assets in restrained eating. Eat Behav 9, 285-293.

56. Sniehotta FF, Schwarzer R, Scholz U et al (2005) Action planning and coping planning for long-term lifestyle change: theory and assessment. Eur J Soc Psychol 35, 565-576.

57. Corrin T \& Papadopoulos A (2017) Understanding the attitudes and perceptions of vegetarian and plant-based diets to shape future health promotion programs. Appetite 109, 40-47. 